\title{
The identity approach for assessing socio-technical resilience to climate change: example of flood risk management for the Island of Dordrecht
}

\author{
B. Gersonius ${ }^{1}$, R. Ashley ${ }^{1}$, and C. Zevenbergen ${ }^{1,2}$ \\ ${ }^{1}$ UNESCO-IHE Institute for Water Education, Delft, The Netherlands \\ ${ }^{2}$ Faculty of Civil Engineering and Geosciences, Delft University of Technology, Delft, The Netherlands \\ Correspondence to: B. Gersonius (b.gersonius@unesco-ihe.org)
}

Received: 20 November 2011 - Revised: 2 March 2012 - Accepted: 16 May 2012 - Published: 10 July 2012

\begin{abstract}
Recent EU guidance on adaptation calls for the enhancement of socio-technical resilience to climate change. However, socio-technical resilience is relatively poorly defined and this makes it difficult to apply in practice. This paper uses the concept of identity as a vehicle to advance the definition and assessment of socio-technical resilience. Identity comprises four aspects (components, relationships, innovation, and continuity) that constitute the minimum of what has to be identified and specified if resilience is to be assessed. Characterising the identity of a socio-technical system requires the conceptualisation of these four aspects in relation to the particular function provided by the system (e.g. flood risk management) and also the identification of the specific variables and thresholds that reflect changes in identity. We have demonstrated the utility of the identity approach, using the example of flood risk management for the Island of Dordrecht, the Netherlands. Based on the results, socio-technical resilience has been redefined as the ability of the system to continue to function as expected in the face of change. This definition implies that a system is resilient when it can deliver performance without a change of identity by continuing compliance with standards and expectations.
\end{abstract}

\section{Introduction: toward a concept of socio-technical resilience}

Enhancing resilience to climate change (i.e. climate proofing; Kabat et al., 2005) is developing as a best practice concept in relation to the planning/modification of flooding systems (see e.g. The EU White Paper on Adapting to Climate Change;
European Commission, 2009). The definition of resilience is, however, open to debate, and this makes it difficult to apply in practice. Resilience is a concept originally developed for ecological systems (Holling, 1973) and has increasingly been used in many studies on social-ecological systems (SES) (Folke, 2006). The reason for extending the use of resilience to SES is that any delineation between social and ecological systems is seen as artificial and arbitrary (Berkes et al., 2000). Rather few studies have applied the concept of resilience with respect to socio-technical systems (STS), such as the flooding system. STS link physical systems (e.g. flood risk infrastructure) with actors (e.g. flood risk management organisations) and rules (e.g. acceptable flood risk standards) in order to provide a particular function (e.g. flood risk management) (Geels, 2004). Given the increasing call for climate proofing, this paper aims to advance the definition and assessment of socio-technical resilience.

In the last two decades, at least two distinct and alternative definitions of resilience have been produced: attractor-based (Gunderson and Holling, 2002) and identity-based (Cumming et al., 2005). The attractor approach defines resilience as the capacity of a system to absorb disturbance and reorganize while undergoing change, and is concerned with the system remaining in the same attraction basin. The concept of an attraction basin refers to the part or condition of the system state space that may be thought of as containing a particular attractor, toward which the system state tends to go. It is therefore the region or condition in the state space where the system would tend to remain in the absence of drivers and perturbations (Gallopín, 2006). A regime shift occurs when a system crosses an ecological threshold to another attraction 
basin. A common characteristic associated with ecological threshold crossings is hysteresis, which means that the system change may be irreversible once a threshold has been crossed, even if the driving force that initiated the threshold crossing ceases (Scheffer et al., 2001). Such a regime shift represents a loss of resilience of the system. The degree of resilience is thus quantified by the magnitude of disturbance that a system can undergo before crossing the limit of the attraction basin (Carpenter et al., 2001). Examples of attractor-based resilience assessment are given in Scheffer et al. (2001).

The identity approach equates resilience with the ability of a system to maintain its identity in the face of change and investigates whether or not the system crosses any key identity thresholds. The concept of identity comprises four aspects that constitute the minimum of what has to be identified and specified if resilience is to be assessed (Brand, 2005): (a) components, which include the structural and nonstructural variables that make up the system; (b) relationships, which are the process or interaction variables that link the components; (c) innovation, which includes the variables that generate change of components and relations; and (d) continuity, which describes the variables that facilitate the continuation of components and relations through time (Cumming et al., 2005). The rationale behind the identity approach is that many variables within the system may change over time, but the specific variables that define its identity must be maintained if the system is resilient (ibid). As such, the degree of resilience is estimated by the potential for a change in identity (and its magnitude) under alternative scenarios for external drivers.

While the attractor approach is useful for assessing resilience of SES, it has an important limitation when applied to STS. This is because STS do not exhibit ecological thresholds, but acceptability thresholds. These set out the expectations of performance of the STS. Here, it is contended that expected performance is best conceptualised in terms of maintaining identity in order to ensure that the STS has adequate resilience rather than considering a set of attractors. The reason for this is that crossing acceptability thresholds does not lead to irreversible system changes; it simply means that an alternative adaptive strategy is required to restore the performance of the STS to its original identity. Hence, the concept of identity is used in this paper as a vehicle to advance the definition and assessment of socio-technical resilience. The application of the identity approach for assessing socio-technical resilience is illustrated here using the example of flood risk management for the Island of Dordrecht, the Netherlands.

\section{Method}

This paper considers socio-technical resilience as a quantitative and measurable concept. When used in this sense, it

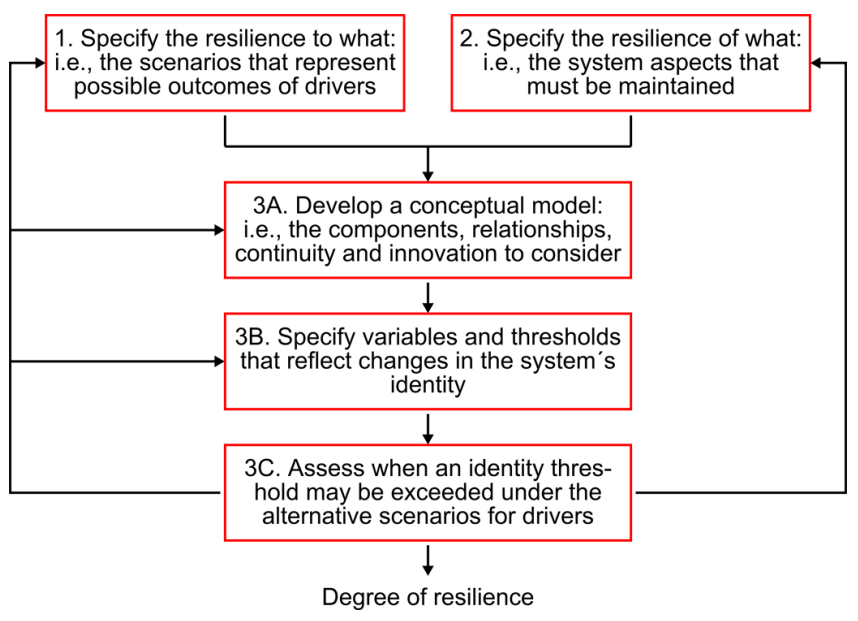

Fig. 1. Flow chart of the identity approach for assessing sociotechnical resilience.

is necessary to specify resilience "to what" (Step 1) and "of what" (Step 2) and, subsequently, to undertake an assessment of the system resilience (Step 3) (Walker et al., 2002). Resilience assessment based on the concept of identity is comprised of three sub-steps (Cumming et al., 2005). Step 3A is to develop a conceptual model. Part of this step is to determine the boundaries, such as the spatial and temporal scales of the resilience assessment. The conceptual model is used in Step 3B to identify the specific variables and threshold values that reflect changes in identity. Finally, Step $3 \mathrm{C}$ assesses the potential for changes in identity under the drivers specified in Step 1. A flow chart of the identity approach for assessing socio-technical resilience to climate change is presented in Fig. 1. These steps are explained below for the context of a flooding system.

\subsection{Step 1: resilience to what?}

The "to what" part specifies the variables that cause change to the flooding system (i.e. the kind of drivers), with particular relevance to their impacts on the object(s) of interest. Because this paper deals exclusively with climate proofing, for simplicity this is taken as the single driver of interest for the resilience assessment. Climate change is expected to result in significant changes in the frequency and risk of flooding in many regions. The Intergovernmental Panel on Climate Change (IPCC) has developed different scenarios of climate change. The SRES scenarios used in the IPCC Third Assessment Report were based on likely greenhouse gas emissions in each scenario, together with an assessment of the likely management of these emissions. More recently, the IPCC has provided estimates of the ranges within which climate changes may occur for global meteorology, given as probabilities (Solomon et al., 2007). Whilst these are useful, for the purpose of resilience assessment, these need to be considered 
in terms of the more regional/local impacts of these changes on the flooding system.

\subsection{Step 2: resilience of what?}

The "of what" part characterises what is being considered as the object(s) of resilience. A critical question in this regard is whether the object of resilience is structural or functional (Smith and Stirling, 2010). Definitions of resilience that make no distinction between structure and function can become problematic, in particular for STS. This is because resilient individual structures at particular scales (e.g. largescale engineering structures or tightly regulated institutions) will often threaten the performance of the function provided by the STS. The aim of resilience management is, therefore, to enhance or maintain the performance of the function of interest and also to preserve those structures (both technical and social) that lead to enhanced performance and not necessarily preserve the existing systems themselves (ibid). In other words, the object of socio-technical resilience is the performance of the function provided: in this case flood risk management. Folke et al. (2010) conclude that sometimes transformations are necessary to reduce this structural resilience in order to gain functional resilience under changed conditions. For example, the transformation from a hard coastal defence system (e.g. a single sea dike) to an integrated hard/soft coastal defence system (e.g. a sea dike with an elevated sandy foreshore) will help to deliver increased flexibility to respond to future uncertainties associated with sea level rise, and, thus, enhance functional resilience (Gersonius et al., 2011).

\subsection{Step 3A: development of a conceptual model}

According to Newman et al. (2011), the flooding system can be considered as a STS: its main function is to provide flood risk management. Therefore, aspects of identity (components, relationships, innovation and continuity) have been selected that relate directly to this function. These are summarised in the next sections and Table 1.

\subsubsection{Components}

Based on the STS perspective (Geels, 2004), the flooding system encompasses not only the physical flooding system, but also the actors that are impacted upon by flooding or responding to flood risk and includes the rules that structure and regulate the associated physical and socio-economic processes. The physical flooding system is comprised of both the engineering structures provided to deal with flood risk and the environment. The actors involved in the flooding system are individuals, groups, and flood risk management organisations. Rules can be categorised as formal, normative and cognitive (i.e. regulations, behavioural norms and knowledge, respectively). Examples of formal rules are regulations, laws, procedures and standards; examples of normative rules

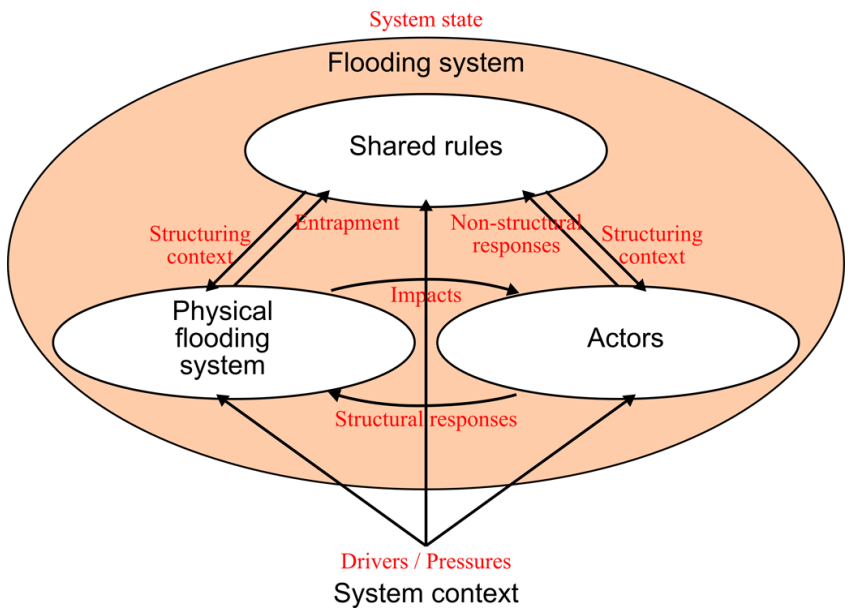

Fig. 2. Simple conceptualisation of the flooding system and its context, with components in oval boxes and relations in arrows.

are values and norms; and examples of cognitive rules are shared belief systems and expectations. Actors in different groups share different kinds of rules, which are referred to as socio-technical regimes (ibid). As an example, different groups have different expectations toward flood risk. Rules are not just shared in or between groups, but can also be embedded in the practice of providing engineering structures and how flood risk is managed. The flooding system is continuously changing because of physical and socio-economic processes (i.e. the drivers), as well as the responses intended to reduce the risk of flooding (Hall et al., 2003). Figure 2 gives a simple conceptualisation of the flooding system with its different components in mutual interaction.

\subsubsection{Functional relationships}

Different relations exist between the system components and between the system and its context (Ottens et al., 2006). These describe how the system components interact or fit together. The causal relations within the flooding system may be considered to be well-understood, and these are generally described using the drivers-pressures-state-impactsresponses (DPSIR) model (e.g. Evans et al., 2004). The state of the flooding system includes the state of the physical flooding system, actors and rules. In any system state, the flooding system has a quasi-stationary level of risk associated with it, where risk is considered as a function of the flood frequencies and impacts. Drivers, pressures and impacts are then considered in terms of how the system state may alter. Drivers and pressures act upon the system state, often resulting in physical and socio-economic changes. This has both negative and positive effects on the level of risk associated with the system state, and this is described by the impacts. The drivers, pressures and impacts may lead to responses, which are diverse adaptations to the structures and processes by the actors. These can be categorised as either 
Table 1. Aspects of identity.

\begin{tabular}{lll}
\hline & Variables & Explanation \\
\hline Components & Physical flooding system & Engineering structures and the environment \\
& Actors & Individuals, groups and flood management organisations \\
& Regulative rules & Laws, regulations, policies, procedures and standards \\
& Normative rules & Values and norms \\
& Cognitive rules & Belief systems and expectations \\
\hline Relations & Causal relations & $\begin{array}{l}\text { Drivers/pressures act upon the system state to create the impacts, to which actors } \\
\text { will develop responses }\end{array}$ \\
& Normative relations & The physical flooding system and actors are structured by rules \\
\hline Innovation & Niche dynamics & $\begin{array}{l}\text { Articulation and refinement of visions, learning processes and build-up of social } \\
\text { networks }\end{array}$ \\
& & $\begin{array}{l}\text { Institutional common sense, regulations and standards, adaptation of lifestyles } \\
\text { to technical systems, and sunk investments in infrastructures and competencies }\end{array}$ \\
\hline Continuity & Regime dynamics &
\end{tabular}

structural or non-structural (European Commission, 2009). Structural responses are engineering-based adaptations to reduce flood risk. Non-structural responses may not require engineering, and their contribution to risk reduction is most likely through changing behaviour through regulation, encouragement and/or economic incentivisation (Taylor et al., 2002). Collectively, the above relate to the performance of the physical flooding system as well as the performance of the actors responding to flood risk.

In addition to the causal relations, normative relations exist between the rules and the physical flooding system and actors. A relation is normative if one component includes a rule that provides a structuring context for the other component (Ottens et al., 2006). Actors use cognitive rules to shape perceptions of the future and hence make decisions on adaptation in the present. Formal and normative rules also influence the behaviour and decisions of actors, as these are embedded in regulatory structures and social/organisational networks. Like the actors, the physical flooding system is structured by rules. For example, acceptable flood risk standards will limit the frequency or risk of flooding to a quantified level.

\subsubsection{Continuity}

Continuity is provided by the linkages and alignments between the different components of the flooding system. These linkages are the result of the responses of actor groups, which produce and reproduce them. Their responses create and maintain the structural and non-structural components. For example, flood risk management infrastructure is built and maintained by flood management organisations; flood risk regulation is created by government; and expectations emerge from the way in which different groups perceive flood risk. The responses of the different actor groups are coordinated and aligned to each other. This inter-group coordination is represented in the concept of socio-technical regimes (Geels, 2004). Socio-technical regimes account for continuity of existing systems through different mechanisms, as explained by Geels and Kemp (2007). Existing systems are stabilised by organisational rules, procedures and cognitive routines (Geels, 2005) and also by regulations and standards (Unruh, 2000). In addition, actors and social networks represent organisational capital and institutionalised power, which contribute to the continuation of existing systems. This is because of interdependent relationships, mutual expectations, organisational commitments and vested interests of existing organisations (ibid). Finally, the underpinning of irreversible investments and the economics of use of the physical subsystems may lead to problems such as a "lock-in" to their use, as non-abandonable or non-adaptable infrastructures for decades into the future (Ashley and Brown, 2009). It is these various mechanisms and structures that contribute to incremental changes in refining existing systems by following particular directions, leading to trajectories that are often path-dependent. Often, however, this kind of change process will lead to greater socio-technical resilience, because, over time, incremental changes can accumulate and result in performance improvements. But it can also lead to reduced socio-technical resilience and maladaptation, where such trajectories are counterproductive to the expected performance of the physical flooding system.

\subsubsection{Innovation}

System innovations emerge in niches as an effect of learning processes and network building. Niches are networks wherein it is possible to deviate from the rules in the existing regime (Rip and Kemp, 1998). The rules in niches are less specified and clear-cut than in regimes; there are only general rules and broad visions. This means there are less 
structuring effects and there is more space for learning (i.e. going in different directions and trying out variety). These general rules and visions become more specified as more is learnt about the new innovation. Furthermore, the social networks in niches are smaller and more precarious than in regimes. The building of social networks and constituencies to support the new innovation is thus an important internal niche process. In summary, niches contribute to innovation, because they provide space for key processes, such as the articulation and refinement of visions, learning processes and the build-up of social networks (Geels, 2004). The innovations in niches are directed to the problems of the existing regime and may eventually be used in the regime or even replace it. This is not easy because the existing regime is stable in many ways, as explained above in relation to the flooding system.

\subsection{Step 3B: specify thresholds of identity}

Step 3B identifies the specific variables and thresholds that reflect changes in identity. For a flooding system to be considered resilient, the variables that define its identity should be maintained under the specified drivers specified in Step 1 . This implies the system can have the same identity while also undergoing change, but only for change up to a critical threshold. A key variable that defines the identity of the flooding system concerns the performance of the physical flooding system, i.e. its capability in terms of flood risk. The critical identity threshold occurs when the system performance is outside the acceptable risk level, as defined by law or decided by the stakeholders. If as a result of climate change, the physical flooding system can no longer deliver an acceptable risk, then the flooding system may be considered as a different system: i.e. it changes its identity. The magnitude of climate change beyond which the system identity changes will then become a fixed point of reference, against which potential boundaries of socio-technical resilience can be assessed (refer to step 3C). Kwadijk et al. (2011) have defined this point as an adaptation tipping point (ATP). Before an ATP is reached, an alternative adaptive strategy is required to restore the performance of the physical flooding system to its original identity. It is of note, however, that the specific quantitative thresholds used to define identity changes will be emergent, ${ }^{1}$ because the standards and expectations may change in the future. It is, therefore, not possible to predict the precise boundaries of socio-technical resilience with any certainty into the future.

\footnotetext{
1 Emergence is defined as "the arising of novel and coherent structures, patterns and properties during the process of selforganization in complex systems" (Goldstein, 1999).
}

\subsection{Step 3C: assess when an identity threshold may be exceeded}

This step typically uses simulation models to determine the potential for a change in identity (and its magnitude) under alternative climate change scenarios. The outcome of this step will provide an estimate of the degree of resilience of the flooding system to climate change. It has been argued in Step 3B that the flooding system has the same identity if the flood risk is maintained at an acceptable level through time. This will depend on the state of the flooding system. The level of risk in a particular system state can be assessed with the help of hydrological and/or hydraulic models. It is, therefore, possible to identify the location of an ATP by assessing the specific boundary conditions (i.e. the system state), under which acceptable flood risk standards and/or societal expectations toward flood risk may be exceeded. This is mostly the same as a sensitivity analysis of the performance of the physical flooding system to future climate conditions. If the flooding system's identity is likely to be changed under these conditions, then the system may lack resilience to climate change in certain respects. If the flooding system is likely to maintain its original identity across a broad range of future climate conditions, then it has a higher degree of resilience to climate change.

\section{Illustrative example: flood risk management for the Island of Dordrecht}

Step 3 of the resilience assessment is illustrated using the example of flood risk management for the Island of Dordrecht, the Netherlands. Dordrecht is the oldest (and was once the most important) city of Holland (the region consisting of the provinces of North Holland and South Holland).

\subsection{Current flood risk management}

Surrounded by a series of rivers and canals, the city of Dordrecht is effectively located on an island (Fig. 3). The Island of Dordrecht lies in the transition zone between a tidal reach and a river regime reach, where the extreme water stages are influenced by both the river discharge and the sea level. The flow direction depends on the discharge of the Rhine and (to a lesser extent) the Meuse. Water flows toward the sea during low tides through the Maeslant barrier in the Nieuwe Waterweg, the Hartel barrier in the Hartelkanaal and the locks in the Haringvliet. The Nieuwe Waterweg and the Hartelkanaal are open outlets, which can be closed off. The discharge at the Haringvliet locks depends on the Rhine discharge at Lobith. The locks are shut when the river discharge is low $\left(<1200 \mathrm{~m}^{3} \mathrm{~s}^{-1}\right)$. The locks are fully open at a Rhine discharge of $10000 \mathrm{~m}^{3} \mathrm{~s}^{-1}$. The flow direction changes when the Rhine discharge at Lobith is larger than $4000 \mathrm{~m}^{3} \mathrm{~s}^{-1}$. From this point onwards, the river discharge starts to dominate the incoming tide flow. 


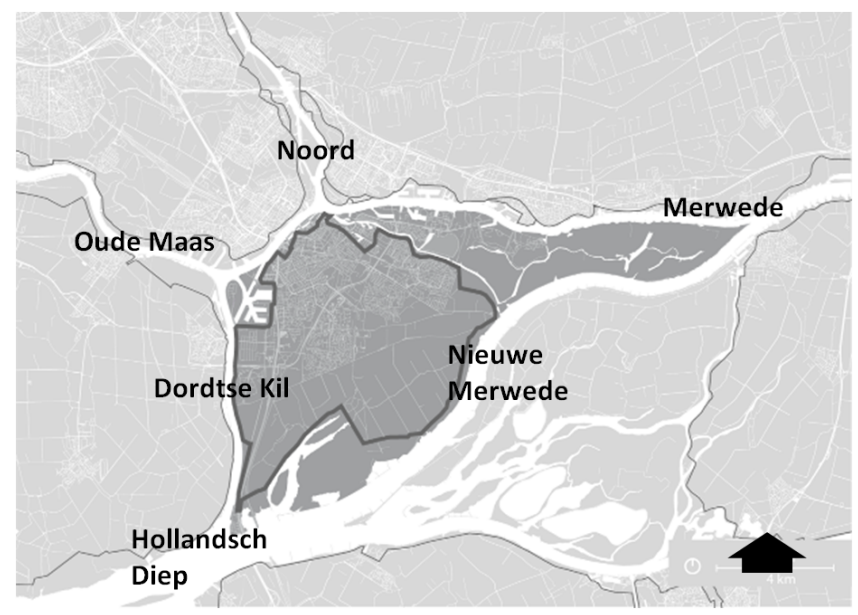

Fig. 3. Rivers and canals surrounding the Island of Dordrecht.

Much of the city of Dordrecht is located in a single dike ring area of about $70 \mathrm{~km}^{2}$, which is protected by a $37.1 \mathrm{~km}$ long dike ring. The latter comprises the system of primary flood defence structures. Protection standards for dike ring areas have been established by national law (VenW, 2010) as the average exceedance frequency of the design water level a flood defence structure must withstand. The legal protection standard for the Island of Dordrecht has been set at 1/2000 per year. This average exceedance frequency, therefore, constitutes a "formal" identity threshold.

The current statutory assessment of the primary flood defences is based on the protection standard and the corresponding design water levels. The findings of the Third Statutory Assessment for the Island of Dordrecht were that $28 \%$ of the flood defences are below standard (due to, among other, changes in hydraulic peak conditions) and require reinforcement (PZH, 2011). These reinforcement measures are part of, or will become part of, the Flood Protection Programme, which aims to strengthen inadequate flood defences over a 50-yr period (IenM, 2011). The application of the 5yr statutory assessment of flood defences and the successful implementation of the Flood Protection Programme are thus considered to be important mechanisms of continuity in flood risk management for the Island of Dordrecht. These mechanisms contribute to the maintenance of the flooding system's identity in the face of change.

Part of the city of Dordrecht is situated outside the primary flood defences: the so-called unembanked areas. These areas are positioned at relatively high elevations in addition to being protected by the Maeslant barrier and Hartel barrier. The historic port area, with its quay heights between NAP (Amsterdam Ordnance Datum) +1.7 until $+2.5 \mathrm{~m}$, is the lowest-lying unembanked area. It is not possible to define "formal" identity thresholds for the unembanked areas, because there are no legal protection standards for these areas. Socially, a critical threshold would exceed the public expectations regarding flood frequency. It is, however, difficult to determine which frequency of flooding is still acceptable and this is recommended for further research.

According to the National Water Plan (VenW, 2009), the residents and users are responsible for taking consequencereducing measures where there is an unacceptable flood risk (i.e. to maintain continuity). This could include using elevated ground floor levels, dry proofing and wet proofing the ground floor. Dry proofing may involve shielding, where the flood water is kept out of the building by installing temporary barriers. Wet proofing, on the other hand, is based on the acceptance of water entering the building and involves using materials that will minimize the impact of flood water on fabric and fixtures.

\subsection{Potential boundaries of socio-technical resilience}

The potential boundaries of socio-technical resilience in the illustrative example are identified (in chronological order)in the following (see also Fig. 4):

1. Climate change and accelerating sea level rise will require even further reinforcement of the flood defences in the future. However, the costs for these reinforcement measures may be very high or the integration into the surrounding areas can be technically too complex and/or socially unacceptable. This is the case for the flood defence structure at the Voorstraat, which is also a street in the historic centre of Dordrecht. At the Fourth Statutory Assessment (2016/2017), the Voorstraat will, most likely, be rejected as a primary flood defence because of inadequate height. Strengthening the Voorstraat in a traditional way is socially unacceptable, as it would result in several years of construction in the heart of the historic city centre and a potential loss of historic character of the Voorstraat. These technical and societal limits may lead to the occurrence of an ATP for flood risk management. Beyond this critical ATP, the performance of the physical flooding system will be outside the acceptable risk level, reflecting some change of regulatory behaviour. This means that the flooding system may change its identity.

2. The frequency of occurrence of high-water situations in unembanked areas will also increase with climate change and accelerating sea level rise. The historic port area of Dordrecht will be among the first unembanked areas to flood. Possible high water in this area in the future would mainly cause disruption and economic damage, although there is only a limited risk of injuries and casualties. As a first estimate, it is anticipated that the frequency of flooding will remain acceptable until 2050 under the high climate change scenario (KMNI'06 $\mathrm{W}+$ scenario) (Hurk van den, 2007). According to the medium climate change scenario (KMNI'06 G scenario), this will occur around 2100. However, further 


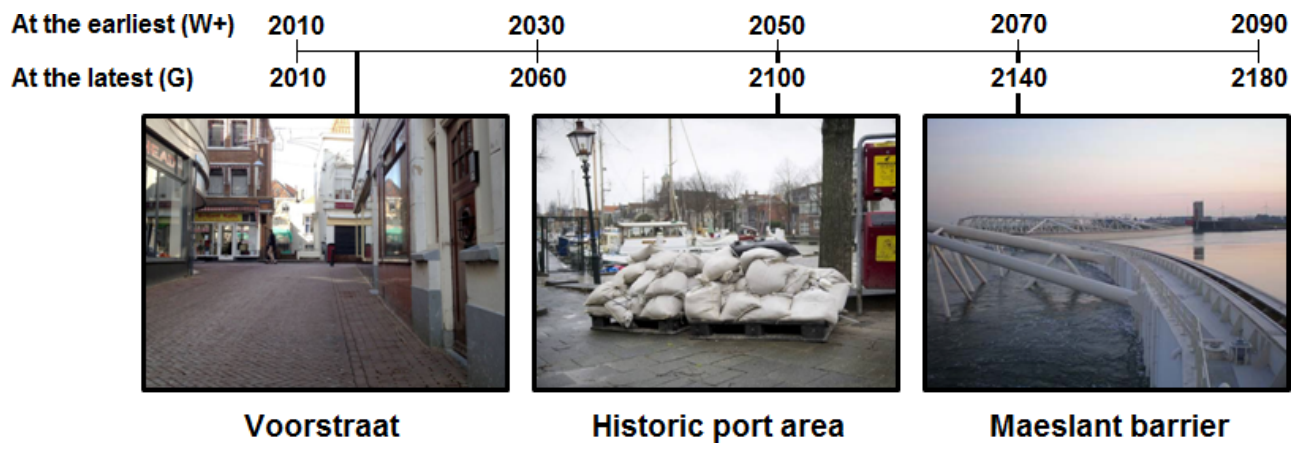

Fig. 4. Timing of the critical ATPs for flood risk management of the Island of Dordrecht.

research regarding the public expectations for flood frequency is needed to determine the timing of this ATP with more certainty.

3. The Maeslant barrier plays an important role in flood risk management for the Island of Dordrecht. The barrier closes if the water level at the outlet of the Nieuwe Waterweg exceeds NAP $+3.0 \mathrm{~m}$ or exceeds $+2.9 \mathrm{~m}$ upstream at Dordrecht. The closing of the barrier ensures that the primary flood defences can meet the legal protection standard of 1/2000 per year. The Maeslant barrier has been designed to cope with $0.25 \mathrm{~m}$ sea level rise and can be easily adjusted to cope with $0.5 \mathrm{~m}$ sea level rise. A sea level rise of $0.5 \mathrm{~m}$ will be reached around 2070 under the high climate change scenario. According to the medium climate change scenario, this will be reached around 2140.

\section{Conclusions}

In the attractor approach, resilience is quantified by the distance of the system from the limit of the attraction basin, which is an ecological threshold. STS do not exhibit ecological thresholds, but acceptability thresholds. These set out the expectations of performance of the STS. Because the crossing of acceptability thresholds does not lead to irreversible system changes, it is difficult to define the expected performance as a set of attractors (as in the attractor approach). The identity approach overcomes this difficulty by conceptualising expected performance based on identity. This paper has demonstrated the utility of the identity approach, using the example of flood risk management for the Island of Dordrecht, the Netherlands. From the results, it has been shown that resilience can be redefined in relation to STS as the ability of the system to continue to function as expected in the face of change. This definition implies that a system is resilient when it can deliver performance without a change of identity by continuing compliance with standards and expectations. It is of note, however, that identity in this context is dynamic, as it responds to changes in standards and expectations. As an example, the flooding system's identity in the present is not at all like it has been in the past, even in living memory (e.g. Newman et al., 2011).

Although the identity approach is useful for defining resilience in relation to STS, it also has limitations. An important limitation is that the selection of identity variables and thresholds is highly subjective and dependent on social values and interests (Cumming et al., 2005). Such normative decisions cannot be made by experts alone (Smith and Stirling, 2010) and should rather be the outcome of meaningful engagement with the actors concerned, for example, via learning alliances (Ashley et al., 2012). Over time, shifts in social values and interests can also alter perceptions of desired trajectories (Voß et al., 2007). This includes shifts in expectations of system performance. Because of this emergence, the threshold value used to define identity changes will also be emergent (i.e. identity is a dynamic property). It is, therefore, not possible to predict the precise boundaries of resilience with any certainty into the future. A main research need is thus to understand how social values and interests evolve over time in response to socio-economic or climatic changes and to consider this in relation to the flooding system's identity. Understanding these change processes will be crucial for managing climate change resilience in relation to STS, not only those dealing with flooding.

Acknowledgements. The authors gratefully acknowledge the support of the EU's Interreg IVB project MARE.

Edited by: B. Barroca

Reviewed by: three anonymous referees

\section{References}

Ashley, R. M. and Brown, R. R.: Entrapped in common sense: why water management by current regimes is not sustainable and what we can do about it, Proc. 9th NESS: Knowledge, learning and action for sustainability, London, 2009.

Ashley, R. M., Blanskby, J., Newman, R., Gersonius, B., Poole, A., Lindley, G., Smith, S., Ogden, S., and Nowell, R.: Learning and 
Action Alliances to build capacity for flood resilience, J. Flood Risk Manage., 5, 14-22, 2012.

Berkes, F., Folke, C., and Colding, J.: Linking social and ecological systems: management practices and social mechanisms for building resilience, Cambridge Univ. Press, 2000.

Brand, F. S.: Ecological Resilience and its Relevance within a Theory of Sustainable Development, UFZ report 03/2005, UFZ Centre for Environmental Research Leipzig-Halle, Department of Ecological Modelling, Leipzig, Germany, ISSN 0948-9452, 2005.

Carpenter, S., Walker, B., Anderies, J. M., and Abel, N.: From Metaphor to Measurement: Resilience of What to What?, Ecosystems, 4, 765-781, 2001.

Cumming, G., Barnes, G., Perz, S., Schmink, M., Sieving, K., Southworth, J., Binford, M., Holt, R., Stickler, C., and Van Holt, T.: An exploratory framework for the empirical measurement of resilience, Ecosystems, 8, 975-987, 2005.

EuropeanCommission: White Paper on Adapting to climate change: Towards a European framework for action, 2009

Evans, E. P., Ashley, R., Hall, J. W., Penning-Rowsell, E. C., Saul, A., Sayers, P. B., Thorne, C. R., and Watkinson, A.: Foresight Flood and Coastal Defence Project: Scientific Summary: Volume I, Future Risks and Their Drivers, London, Office of Science and Technology, 2004.

Folke, C.: Resilience: The emergence of a perspective for socialecological systems analyses, Global Environ. Chang., 16, 253267, 2006.

Folke, C., Carpenter, S. R., Walker, B., Scheffer, M., Chapin, T., and Rockström, J.: Resilience thinking: integrating resilience, adaptability and transformability, Ecol. Soc., 15, 20, available at: http://www.ecologyandsociety.org/vol15/iss4/art20/, 2010.

Gallopín, G.: Linkages between vulnerability, resilience, and adaptive capacity, Global Environ. Chang., 16, 293-303, 2006.

Geels, F. W.: From sectoral systems of innovation to socio-technical systems:: Insights about dynamics and change from sociology and institutional theory, Res. Policy, 33, 897-920, 2004.

Geels, F. W.: Technological transitions and system innovations: a co-evolutionary and socio-technical analysis, Edward Elgar Publishing, 2005.

Geels, F. W. and Kemp, R.: Dynamics in socio-technical systems: Typology of change processes and contrasting case studies, Technol. Soc., 29, 441-455, 2007.

Gersonius, B., Morselt, T., van Nieuwenhuijzen, L., Ashley, R., and Zevenbergen, C.: How the failure to account for flexibility in the economic analysis of flood risk and coastal management strategies can result in maladaptive decisions, J. Waterw. Port CASCE, accepted, doi:10.1061/(ASCE)WW.1943-5460.0000142, 2011.

Goldstein, J.: Emergence as a construct: History and issues, J. Complexity Issues in Organizations and Management, 1, 49-72, 1999.

Gunderson, L. and Holling, C.: Panarchy Synopsis: Understanding Transformations in Human and Natural Systems, Island Pr, 2002.

Hall, J. W., Meadowcroft, I. C., Sayers, P. B., and Bramley, M. E.: Integrated flood risk management in England and Wales, Nat. Hazards Rev., 4, 126-135, 2003.

Holling, C. S.: Resilience and Stability of Ecological Systems, Annual Rev. Ecol. System., 4, 1-23, 1973.

Hurk van den, B.: New climate change scenarios for the Netherlands, Water Sci. Technol., 56, 27-33, 2007.
IenM (Ministry of Infrastructure and the Environment): Basisrapportage van het 2e Hoogwaterbeschermingsprogramma (HWBP2), 2011.

Kabat, P., van Vierssen, W., Veraart, J., Vellinga, P., and Aerts, J.: Climate proofing the Netherlands, Nature, 438, 283-284, 2005.

Kwadijk, J. C. J., Haasnoot, M., Mulder, J. P. M., Hoogvliet, M., Jeuken, A., van der Krogt, R. A. A., van Oostrom, N. G. C., Schelfhout, H. A., van Velzen, E. H., and van Waveren, H.: Using adaptation tipping points to prepare for climate change and sea level rise: a case study in the Netherlands, Wiley Interdisciplinary Reviews, Climate Change, 2011.

Newman, R., Ashley, R., Molyneux-Hodgson, S., and Cashman, A.: Managing water as a socio-technical system: the shift from "experts" to "alliances", Proceedings of the ICE - Engineering Sustainability, 164, 95-102, 2011.

Ottens, M., Franssen, M., Kroes, P., and Van De Poel, I.: Modelling infrastructures as socio-technical systems, Int. J. Critical Infrastructures, 2, 133-145, 2006.

PZH (Province of South Holland): Derde Ronde Toetsing Primaire Waterkeringen, Dijkringgebied 22, Eiland van Dordrecht, 2011.

Rip, A. and Kemp, R.: Technological Change, edited by: Rayner, S. and Malone, E. L., 1998.

Scheffer, M., Carpenter, S., Foley, J. A., Folke, C., and Walker, B.: Catastrophic shifts in ecosystems, Nature, 413, 591-596, 2001.

Smith, A. and Stirling, A.: The politics of social-ecological resilience and sustainable socio-technical transitions, Ecol. Soc., 15, 11, available at: http://www.ecologyandsociety.org/vol15/ iss1/art11/, 2010.

Solomon, S., Qin, D., Manning, M., Alley, R., Berntsen, T., Bindoff, N., Chen, Z., Chidthaisong, A., Gregory, J., and Hegerl, G.: Climate Change 2007: The Physical Science Basis, Contribution of Working Group 1 to the Fourth Assessment Report of the Intergovernmental Panel on Climate Change, 2007.

Taylor, A., Wong, T., and CRC for Catchment Hydrology: Nonstructural stormwater quality best management practices: an overview of their use, value, cost and evaluation, CRC for Catchment Hydrology, 2002.

Unruh, G. C.: Understanding carbon lock-in, Energ. Policy, 28, 817-830, 2000.

VenW (Ministry of Transport, Public Works and Water Management): National Water Plan, available at: http://english.verkeerenwaterstaat.nl/english/topics/water/ water_and_the_future/national_water_plan/ (last access: 2 March 2012), 2009.

VenW (Ministry of Transport, Public Works and Water Management): Water Act, available at: http://www.rijksoverheid.nl/ documenten-en-publicaties/rapporten/2010/02/01/water-act. html (last access: 2 March 2012), 2010.

Voß, J. P., Newig, J., Kastens, B., Monstadt, J., and Nölting, B.: Steering for Sustainable Development: a typology of problems and strategies with respect to ambivalence, uncertainty and distributed power, J. Environ. Pol. Plan., 9, 193-212, 2007.

Walker, B., Carpenter, S., Anderies, J., Abel, N., Cumming, G. S., Janssen, M., Lebel, L., Norberg, J., Peterson, G. D., and Pritchard, R.: Resilience Management in Social-ecological Systems: a Working Hypothesis for a Participatory Approach, Conserv. Ecol., 6, 14, available at: http://www.consecol.org/vol6/ iss1/art14/, 2002. 